\title{
Breaths, Falls, and Eddies in All This Can Happen: A Dialogue
}

Erin Brannigan, University of New South Wales, Sydney

Cleo Mees, Macquarie University, Sydney

\begin{abstract}
Dancefilm muddles the paradigms that would position film as an order of production controlling all cinematic motion (including camera movement, film speed, editing etc.), and dance as motion, liberated and encompassing any-movement-whatever. David Hinton and Siobhan Davies' experimental film, All This Can Happen (2013), draws text, image, and edit together via a poetics that is of the order of the choreographic. In a dialogue that echoes the collaborative spirit of the film, Erin Brannigan and Cleo Mees explore the corporeal and choreographic sensibilities at work in All This Can Happen, recognizing dynamics of breath and weight in various aspects of the film's composition, including the movements of the bodies on screen, the qualities of the edit, and the text of Robert Walser's original novella (on which the film is based). In exploring these corporeal-cinematic qualities, the authors work across and soften the dance-film binary described above.
\end{abstract}

Keywords: corporeality, cinema, falling, breath, choreography

This article was devised as a to-and-fro dialogue between the two authors in the spirit of the interdisciplinary, artistic dialogue between David Hinton and Siobhan Davies. ${ }^{1}$ Thus, the direction the article would take could not be anticipated and has resulted in a text that reveals our shared interest in experimental composition, as well as engages with film's content, including the archival footage and Walser's text. ${ }^{2}$ The experiment owes something, in this respect, both to what we describe as the "unanchored" nature of Walser's text and the choreographic experiment undertaken by Hinton and Davies, the latter of which undoes any binary concepts of dance and film that persist in practice and theory. These are the parameters of our contribution to the rich field of discourse now surrounding the film.

\section{The Choreographer and the Filmmaker}

ERIN: Described as "a flickering dance of intriguing imagery," All This Can Happen is the product of a collaboration between a filmmaker and a choreographer. ${ }^{3}$ Departing from the traditional relationship in such interdisciplinary encounters between content (the choreographic) and form (the filmic), Davies' contribution is not primarily evident 
in the diegetic world; there are no sequences of dancers performing her choreography as in some of her past dancefilms. Instead, it is woven throughout every aspect of the film, from the choice of archival clips to their composition on screen. Equally, Hinton's contribution is not limited to the adaptation of choreographic material for the screen (as in his work with Lloyd Newson, for example) ${ }^{4}$; his deep and rich history in collaborative dancefilm productions is apparent in a project that turns archival film into a cine-dance.

While this is clearly a film with filmic characteristics, a more challenging point to argue is how the film evidences the choreographic work undertaken in process. How do the disciplinary skills of dance figure amongst the strategies, techniques, and paradigms of the cinema? This was a question underlying Dancefilm ${ }^{5}$, and such questions have returned more recently in a slightly different form in debates around the new collaborations between choreography and the gallery. In these discussions, what seems to be new is the idea that all the arts can "do" choreography, and this would be true if the definition is as broad as French curator Alexandra Baudelot's- "dance is first and foremost a question of the body, languages, and frames." ${ }^{6}$

Rather than proffering definitions of dance and choreography, can we think about how key choreographic terms and strategies such as weight, breath, tone, and flow are apparent in the film's composition? ${ }^{7}$ Together with tension, force, rhythm, texture, and energy, these terms are directly related to the physiological operations of the body and constitute discipline-specific variables for dance. How is dance-the discipline with the most advanced understanding of the role of the body, its medium in both the production and reception of a work of art-evidenced in All This Can Happen (ATCH) in its evocation and expansion of the thinking, writing, and walking that are at the heart of the film?

CLEO: An additional question that presents itself here is this: which dance, or whose dance, we are examining? Perhaps there are multiple dances at work in the film, if we consider it not only as a digital audiovisual object, but as an entity with various life stages and dimensions of production and reception. To name some of the dances that might be at play in the film we have, first, the dancing-thinking involved in assembling it, a process of selecting and then "choreographing" video material in the editing suite which quite possibly required that Hinton and Davies empathize kinesthetically with the movement evolving before them on their computer screens. ${ }^{8}$ There is also the dance that happens when viewing the film as an audience member, an experience that again involves empathizing with the movement on screen and simulating that movement in the body, even if only on a barely perceptible neurological level. Finally, there is the dancing surface of the video itself-digital, screen-bound, twodimensional—as well as the dance of the film's richly textured soundtrack. 
Choreographer William Forsythe writes that "a choreographic object is not a substitute for a body" -in other words, that the "choreographic object" is not synonymous with the human body. ${ }^{9}$ In his essay, Forsythe cracks open the possibility of transferring "choreographic thought" beyond the body, to manifest "in another durable, intelligible state," such as his installations, or in sculpture or film. ${ }^{10}$ This is not to say that such objects completely jettison corporeal qualities; for instance, his installations transfer elements such as balance, weight, buoyancy, and tension into insentient materials such as metal, rope, and plastic. In the same way, choreographic terms which engage the dancing body, such as those you list-weight, breath, tone, energyapply readily to film. Film scholar Yvette Biro, for example, refers to breath when describing the rhythmic contours of narrative films over time. ${ }^{11}$ She writes of inhalation and exhalation when tracing the movement between constancy and upheaval, between tension and release, in the films she analyses. I would say that we can treat this film as a body of sorts, a body that breathes and falls, and is subject to gravity.

ERIN: So in considering ATCH as a choreographic object, this becomes our inquiry; at the heart of the choreographic is the body-mind, so where is this evidenced in the film? Then following this is the question: what corporeal, or dance-based knowledges are evident in the film's form? And how can we account for its composition as a choreography? So we are sliding around between process speculation, compositional analysis, and spectator theory. Asking how the film mobilizes a choreographic sensibility emphasizes how the filmic performance-in its expanded definitionbecomes, what philosopher Jean-François Lyotard calls, a "somatography." ${ }^{12}$ Film theorist Laleen Jayamanne writes,

In film the lighting, editing, camera distance and movement are equally potent "performers," so that one could talk of filmic performance as including all these technical elements. These elements can transform the phenomenal body to such an extent that one could say that the body that cinema materializes did not exist prior to the invention of film. ${ }^{13}$

Perhaps this is what you categorize as the 3rd dance in the film-the dance of the surface of the video.

So the body of the filmic performance is constituted through a multiplicity of technical and human elements, something demonstrated again and again in experimental dancefilms. For Lyotard, the work of art and the viewer encounter each other where the affective force of the creative gesture impacts the body of the spectator, preceding and existing independently of thoughts, actions, and feelings. ${ }^{14}$ In the case of experimental film, he refers to the site where this encounter takes place as "a corporeal mise en scène"-somatography. Mise en scène is defined by Lyotard as "to stage," and what is being staged is "on and for bodies, considered as multi-sensory 
personalities." ${ }^{15}$ In the corporeal mise en scène, affect is not there, pre-existing in the work, nor here as a familiar end result, a recognizable feeling. It is in pre-cognized effects that we can locate affects, and those effects are physical and in the domain of somatic intelligence, where bodily knowledge demands attention but where discourse fails. Recognizing and understanding the contributions of corporeality as an alternative source of knowledge is a major contribution of dance to the humanities, and fields like cinema studies are catching up. ${ }^{16}$

Reading Michael Taussig (on Benjamin on Duchamp), Vivienne Sobchack, Jennifer Barker, and Steven Shaviro on the tactility of vision, it seems clear that in a discussion of dancefilm and spectatorship, the plurisensoriality of dance must weigh in. This aspect of dance is well articulated by French kinesiologist and movement researcher Hubert Godard:

For a dancer, [plurisensoriality] is fundamental; dancers must be able to reproduce a movement they have seen, match it with a musical sound, and modulate their motor function accordingly [...] the work carried out in contemporary dance aims to do away with this compartmentalization [of the senses] which is caused by the catastrophe of language, by history. ${ }^{17}$

If choreography engages a plurisensorial mode of composing, executing, and viewing - perhaps before or beside structured thought and named feelings-let this guide our search for the choreographic in $A T C H$ - specifically in the details of the filmic performance.

But before doing so, I'd like to add to the categories of dances in ATCH that you have outlined-the dance of composition, the dance of spectatorship, and the dance of the filmic performance-the dance of Walser's text. As a part of the soundtrack, it dominates in the way only narrative texts can, appearing to order all of the heterogeneous elements at play.$^{18}$ However, the text itself could be considered a form of writing-dancing due to the weight given to descriptions of his walking style ("my steps were measured and calm", "a delicate, prudent walk... a subtle, circular stroll") and of the gestures of himself and others ("a juvenile, foolish shout of joy burst from my throat," "bold, elegant, courteous waving"), but also the description of his own, overarching movement from city to countryside and back again which shapes the text both narratively and emotionally. ${ }^{19}$ The tone of the text is also dancerly; that the mood of the protagonist is so aligned with the surrounding environment speaks of a corporeal sensitivity to his immediate physical surroundings, described as it is experienced in a self-aware present. This aligns with the characteristic of a dancer's plurisensorial awareness of their own movement in space-time. ${ }^{20}$

CLEO: Some terms for me that may prove rich in relation to this film... To stage: to see this film as the "staging" of an original text, almost like the staging of an opera-an assembly of forces that create an "effect of reality" ${ }^{21}$ which has the power to affect 
viewers, bodily. Somatography: the inscription of a written text onto bodies; the raising up of that text into verticality and ephemerality.

\section{Breath}

CLEO: The film opens with bated breath - an unsteady rumble in its gut (and in mine), the distinct absence of speech. Monochrome footage: a man in a loincloth writhes stiffly on the floor, unable to lift himself to standing; another lies on a bed, his head and neck manipulated in all directions at impossible speed by a pair of hands belonging to someone at his bedside. Occasionally he looks straight at us in freeze frame. A brooding quiet hangs over us, like a bank of dark storm clouds some ways away. What waits to bear down upon us?

All this is released suddenly with the ripping-tinkling of louvres pulled up, flooding the frame with morning light. The sounds of life in a busy street, the view of the street from a second-story window. Speech. The writer converses with us, describes his desire to take a walk, to leave his room of phantoms behind for a while. We plunge into the morning with him, now breathing easier in the acute relief of walking, and of mornings.

Breath is held and released in this way at several points throughout the film: anticipation, tension, and-after this holding in-an exhalation. A release back into forward movement and easier breathing.

Progressions like these-of bated breath followed by exhalation-seem to roll us over from one chapter of the walk into the next. Each exhalation may also signify a return to an equilibrium of sorts. As the writer himself observes towards the end of the film, he swings regularly in and out of equilibrium, in and out of the forward trajectory of walking, and in and out of relative emotional contentment:

Mysterious and secretly there prowl at the walker's heels all kinds of beautiful subtle walker's thoughts, such as make him stand in his tracks and listen. He will again and again be confused and startled by curious impressions and bewitchings of spirit power. He has the feeling that he must sink all of a sudden into the earth, or that before his dazzled eyes an abyss has opened. Earth and heaven suddenly stream together and collide into a flashing, shimmering, obscure nebular imagery; chaos begins, and the orders vanish. Convulsed, he laboriously tries to retain his normal state of mind; he succeeds, and he walks on, full of confidence. ${ }^{22}$

\section{Weight: Eddies and Falling}

CLEO: This loss and recovery of equilibrium - the opening of an abyss, the writer's effort to retain a "normal state of mind," and the eventual recovery-recurs throughout the film. I wonder if we could even say it characterizes the rhythmic 
contour of the film: walking, falling, recovery; walking, falling, recovery. ${ }^{23}$ The fall is seductive, as falling so often is - the writer is pulled out of his forward trajectory by some interruption and spirals deliciously into eddies of mental meandering, social interaction, and emotional intensity.

I draw the term "eddy" from my experience as a dancer participating in the "Painted Space Impro Exchange," an improvisation research laboratory held in Sydney in 2012. At one point in this workshop, facilitators Tess de Quincey and Martin del Amo set participants the task of walking in straight lines exclusively for a set time, and then of walking in curves exclusively for a set time. Walking in curves, many of us found that it was easy and indeed very tempting to fall into circular, spiraling walking patterns that had us turning repetitive circles around ourselves. This coiled walking felt to my body like a gentle vortex, a constant falling inwards while only just managing to keep myself upright. There was a sense of risk, that I might begin to spiral so steeply that I lost my balance altogether. At one point someone described these spirals as "eddies," and the term stuck for me, at least. Several of us reflected that circling in these small whirlpools, or eddies, was pleasurable, and that it took effort to move on from an eddy, to push our bodies out of falling and into a less steeply curved path by which we could travel across the room again.

My sense in watching this film is that the writer, at every new meeting or stimulus, "swerves" from his forward path into a curve, and enters an eddy. ${ }^{24}$ Leaning into the spiral-like pull of his situations, he reaches surprising emotional highs and lows in which passionate descriptors of his feelings are heaped one atop the other, to a circling effect. For example, his nostalgic musings about his childhood, when he sometimes received a "well-deserved thrashing," ${ }^{25}$ lead him headlong into the declaration that men who cut down their beautiful nut trees deserve to be thrashed, and this in turn leads him to mourn the exchange of these beautiful trees for "despicable, wicked, foolish, money." ${ }^{26}$ The heaping up of these descriptorsdespicable, wicked, foolish-suggests an eddying, a mesmeric circling around the same thought or feeling.

A reading of Walser's original novella suggests that these curves are made steeper by the filmmakers' editing of the written text. The narration in the film is an abridged version of the original, which is longer and makes its way towards emotional climaxes at a more gradual pace. As sections of the original text are edited out of the voice-over narration, the writer's emotional inclines become steeper and more jagged, his ascents into passion more dramatic, and each climax more surprising for its quick arrival.

Some of these eddies are subtle and not overly disruptive, for example the writer's observations on speed early in the film, which gently carry him into a reflection on his own love for slowness. "In fact, I love repose, and all that reposes," he muses, "I love 
thrift and moderation and am, in my inmost self, in God's name unfriendly towards any agitation and haste." ${ }^{27}$ This eddy in the writer's thinking occurs as he continues to walk and does not throw his emotional equilibrium as much as other encounters do. A more disruptive encounter is the writer's lunch date at the home of his friend, Frau Aebi. Her strangely devoted gaze, combined with her insistence that he let her cut him another slice of meat, unsettle the writer and set into motion a visceral, erotic, surrealist meltdown. We enter into a visual world of dripping and squirting, of suggestively unfolding flowers, of gaping mouths and mouth-like rings of mold growing on old meat, of crackling insects and sprouts and roots. "Terrible woman!" the writer cries out, "What do you want with me?" He is released from this nightmarish vortex at once, when Frau Aebi laughs and confesses that she had merely "permitted herself a joke." ${ }^{28}$ On screen, a woman with a genuine face laughs and pats a man on the back, daylight filtering in from left of frame. We are back in the real world, back on solid ground. Exhale.

Trains of thought like the writer's might be common in the wandering minds of walkers. But I wonder if some sort of falling, some succumbing to an idea or a feeling to follow it through to its ultimate conclusion, must take place to bring us to emotional intensities of this degree..$^{29}$

ERIN: And through the creative process we are seeing this falling in a dual mode here; this pattern in the thinking/writing alongside the eddying or circling that the images represent. Hinton has described how the artists were hoping to both mimic a stream of consciousness that is inherent in the random occurrences that unfold for the writer, and also give a sense of the multiple layers of information occurring at any given moment for a subject moving through the world. ${ }^{30}$ The comprehensiveness of the content-covering music, money, fashion, food, politics, sex, and love-is proliferated yet again through images that extend, deepen, and derail stable thematics. Tomzack: storm, dust, rubble, smoke, owls, fire. Death: a sleeping girl, a butterfly, a tombstone, a pale neck and head falling back, a bird. Plurality at the level of the visual storytelling matches the highly attuned subjectivity of the dancer who acts as a sensitive mediator between perceptions and actions, stimuli and choices, which happen not in linear progressions but overlapping, corresponding, clashing, and collapsing. A version of this passage from The Walk is set against an extended montage of male folk dancers, the most explicit occurrence of dancing in the film:

Earlier walks came before my eyes. But the wonderful image of the present swiftly became a feeling which overpowered all others. All notion of the future paled and the past dissolved. In the glowing present, I myself glowed. From every direction and distance, all things great and good emerged brightly with marvelous, uplifting gestures. In the midst of this beautiful place, I thought of nothing but this place itself; all other thoughts 
sank away [...] I fell away from the surface, down into the depths, which I recognized then to be all that was good. ${ }^{31}$

This condition of falling-into a series of events, an emotional eddy, a montage of images constituting an affective field-is set up in the film's introduction through footage aptly described by Brian Bahouth as "wrenching." 32 Sourced from the Wellcome Institute, this footage of "shell-shocked" WW1 returned soldiers is set against Jules Marey's pre-cinematic, sequential images of functional and exemplary movement which "drops in" throughout the film. The returned soldiers are afflicted with abnormal muscular tensions that prohibit efficient locomotive movement, often resulting in the men falling out of their attempt to walk, caught by others off camera or ending on the ground. This footage is part of a series of images in the film of human suffering: a child is beaten with a stick as he lies curled up on the floor, a white neck is dangerously exposed against a black background as the head lolls back and out of frame. Other things fall in the film - trees, paper, water-and this series of images creates a "negative" set juxtaposed against images of jumping that are joyfulchildren playing leapfrog, skipping, and grown men inexplicably flying up above a crowd of happy soldiers closer to the camera. These latter images belong with the series of tiny birds flying out of hands, gently released by the fat fingers of working men.

As you state, falling also evokes pleasure and the standard mode of the narrative is to be at one extreme or the other. For dancers working at the turn-of-the-twentiethcentury, a new, pleasurable and creative relationship with gravity, weight, and the ground opened up new dimensions for the body moving through space and time. The vertical orientation of classical ballet was challenged by the terrestrial choreographies of Doris Humphrey, Martha Graham, and Mary Wigman. So falling, and the associated muscular release, is at the heart of what French dance theorist Laurence Louppe calls "the birth of contemporary dance" at the beginning of the 20th century. ${ }^{33}$ The release of muscular tension and a less domineering partnership with gravity produced dance images of bodies falling through space and engaging with floor work. Again I turn to Godard, who describes the subversion of our foundational, efficient muscular habits that this new dance form undertook:

The essential task of the tonic muscles is to inhibit falling [...] In order to make a movement these muscles have to release. And it's in this release that the poetic quality of the movement is generated [...] Why are we moved when someone dances, when they put so much at stake in terms of their stability [...]? Because these activities refer to the history that is wholly inscribed in our bodies, in the very muscles that hold us upright. ${ }^{34}$

The filmic form of All This Can Happen follows the risks of extremes that are experienced by a writer whose equilibrium lacks an anchor. Consequently, the 
choreographic organization of images and footage extends beyond commentary to succumb to a poetics that mimics the experience of falling beyond what is safe, efficient, and stable.

CLEO: This process of fall and recovery is also fundamental to the physical mechanics of walking. As Rebecca Solnit points out, to take a step is to momentarily lose and then recover one's balance-stretching one foot forwards in the air, launching one's weight off the back leg, and, for an instant, free-falling until the front foot makes contact with the ground and deftly absorbs the shock of landing. ${ }^{35}$

\section{The Edit: Co-Performing Panels}

CLEO: For much of the film, its 16:9 frame is split into various panels containing moving images-a spatial montage. As the edit progresses chronologically, different moving-image panels take up varying proportions of the screen (halves, eighths, one third, two thirds). The remaining space between the panels is black, giving the impression of a slim dark frame that separates (and changes shape with) the images.

Alongside the pattern of fall and recovery, falling happens in an editing sense throughout the film, through movement that spills in stops and starts across the variously split screen. The moving-image panels appear to be in conversation with one another. They do not always display motion at the same time; in fact, they often move one at a time, tag-teaming so that one image moves while the other images hold still, waiting their turn in freeze frame. At times, the panels fall into unison, into syncopation, into canon. They make room for each other, allow each other to become the momentary focus of attention. They enact repetition, performing the same motion as each other or performing the same motion with a slight and deliberate variationfor example, depicting the same scenery three times but from different angles. Motion frequently cascades across the screen, from left to right or right to left. Several of these interactions converge beautifully about twelve minutes into the film, where three equidistant panels show a man working knee-deep in a field.

Observing these panels, I am again reminded of an experience I had dancing recently. I worked on a dance residency for Australian independent dancer Patricia Wood, along with one other dancer, Rhiannon Newton, at Critical Path in early 2015. The three of us improvised with a limited range of movement options in a square space marked out on the floor-a frame of sorts. Working uninterrupted for up to forty minutes at a time, we found ourselves in a constant, speechless dialogue, anticipating when and how the other two dancers might move and letting this influence our own movements. Sometimes we worked to contrast each others' movements, at other times we worked to find unison. In reflection, we agreed that we were repeatedly met with choices like now/not now, I'm waiting for you/I'm not waiting for you, and to synchronize/to diverge. 
I am drawn to the idea that the panels in ATCH's spatial montage are co-performers, constantly falling in and out of step with each other, constantly meeting choices of now/not now and to synchronize/to diverge. The slabs of moving image that share the frame at any given moment resemble the three of us dancing in that designated square at Critical Path. Now moving in unison, now moving in syncopation or in canon; now creating duplicities by depicting identical pieces of footage, now creating contrast by depicting non-identical pieces of footage. Enacting an "I go, and then you go," and a "you go, and then we go," and a "you're doing this, so l'll do that," and an "I'm going to do what you're doing." Always coming head-to-head with chance, toowith surprises, unexpected collisions, and coincidences.

This interpretation risks anthropomorphizing the image panels in ways that some might find problematic. Rather than anthropomorphize the film, then, we could also attribute this dancing-thinking to the makers, Hinton and Davies, who lived through these questions and improvisations in the editing suite.

Falling, in an editing sense, then, has to do with the ways the image panels fall into (and out of) step with each other in order to create a dance on the two-dimensional plane, a dance between independent and collaborating video panes. It has to do with the way movement falls across the screen, quite literally, through the canonical starting and stopping of motion across different image panels.

ERIN: These choreographic strategies you have identified in the edit-unison, syncopation, canon, repetition, variation, synchronization, and divergence-are made richer and more complex through the play between movement and stasis and also fragmentation and juxtaposition. The use of still (both freeze frames and photographs) and moving images (both film footage and camera pans over stills) provide a powerful choice amongst the plethora occurring on multiple levels. The stillness "shuts up" the film - and often the narrator-as we go deeper with an image; the face of a boy turned to the camera, dark with anger or frustration, appearing after the disturbing footage of the child being beaten. Or the sleeping face of a girl with a tear suspended in the corner of her eye set against an image of a butterfly.

CLEO: This reminds me of something else Biro writes about, and that is speed-not speed in the sense of quick cutting or a fast-paced narrative, but speed as bold spacetime compressions and associations created through jump cutting and the juxtaposition of carefully selected, contrasting images. Biro describes high-speed editing as the art of evoking absent, imagined content through the selection and arrangement of powerful images heavy with potential meanings. ${ }^{36}$ In encountering such image clusters-now in motion, now in stillness-the viewer is invited to engage their imagination and to creatively contribute to the available material.

ERIN: To dance with it. 


\section{How does the film dance with me?}

CLEO: And here we return, almost verbatim, to one of the first questions you asked: how does the film dance with me? Lyotard's thoughts around somatography and mise en scène continue to feel pertinent.

Somatography: the transcription of a written text onto bodies, for bodies. Walser's text: written onto the bodies that fall and fly through the archival images; written onto all the individual elements of production that together (per)form the body of the film; written onto this animate entity that breathes and throws its weight around, entering narrative eddies and pouring itself spatially across the screen. (Here we are back at another question you posed, about how choreographic elements like weight and breath figure in a film's composition -it seems that they figure in so many ways!) And all of this for our bodies: we, here, dancing in our seats as we watch, listen, and feel.

To stage- "mettre en scène" - describing that ephemeral, fertile zone between artwork and audience in which affective exchanges are possible. As you said earlier, in the corporeal mise en scène affect is not there pre-existing in the work, nor here as a familiar end result, but where the work of art and the viewer encounter each other on a pre-cognitive, physical level. So this film "dances with us" in the sense that it participates with us in an encounter in which affect happens, in which different dances happen, in which all of it can happen.

\section{Biography}

Dr. Erin Brannigan is Senior Lecturer in Dance at the University of New South Wales and works in the fields of dance and film as an academic and curator. Recent publications include Moving Across Disciplines: Dance in the Twenty-First Century (Sydney: Currency House, 2010), Dancefilm: Choreography and the Moving Image (New York: Oxford University Press, 2011) and Bodies of Thought: 12 Australian Choreographers, co-edited with Virginia Baxter (S.A: Kent Town: Wakefield Press, 2014). Erin was the founding Director of ReelDance (1999-2008) and has curated dance screen programs and exhibitions for Sydney Festival 2008, Melbourne International Arts Festival 2003, and international dance screen festivals.

\section{Email: e.brannigan@unsw.edu.au}

Cleo Mees is completing a practice-based $\mathrm{PhD}$ in dance and filmmaking at Macquarie University. She writes performance reviews for RealTime arts magazine and creates video documentation for creative residencies and performances in Sydney. Cleo's 
dance practice is informed by BodyWeather and Contact Improvisation. She has collaborated on local dance-, design- and music-video projects with composer Harrison Harding and designer Adam France, participated in dance residencies and intensives, and worked as cinematographer on local documentaries. She also writes, shoots, and edits her own essay films, which explore her interdisciplinary research interests.

Email: cleo.mees@mq.edu.au

\section{Notes}

' Siobhan Davies Dance, "All This Can Happen."

${ }^{2}$ Walser, The Walk.

${ }^{3}$ Siobhan Davies Dance, "All This Can Happen."

${ }^{4}$ Dead Dreams of Monochrome Men (1990), Strange Fish (1992).

${ }^{5}$ Brannigan, Dancefilm.

${ }^{6}$ Baudelot, "Choreographic Dispositifs," 182. However, we know that choreography can also appear "off" the body, in line with William Forsythe's "choreographic object." (Forsythe, "The Choreographic Object," unpaginated.).

${ }^{7}$ Louppe, Poetics of Contemporary Dance.

${ }^{8}$ Gallese and Guerra write about the central role of kinesthetic empathy and what they call "embodied simulation" in filmmaking and film viewing; Pearlman writes about the same in relation to film editing specifically and suggests, like Gallese and Guerra, that kinesthetic empathy plays a key role in the editing process (Gallese and Guerra, "Embodying Movies," 2012; Pearlman, "The Rhythm of Thinking," 2004.).

${ }^{9}$ Forsythe, "The Choreographic Object," unpaginated.

${ }^{10}$ Ibid.

${ }^{11}$ Biro, Turbulence and Flow, 35-36.

${ }^{12}$ Lyotard, "The Unconscious as Mise-en-Scène," 88.

${ }^{13}$ As cited in Stern, "As Long As This Life Lasts,"18.

${ }^{14}$ Lyotard, "Gesture and Commentary," 45. It should be noted that Lyotard links affect directly to "feeling," while Deleuze insists that the two terms refer to discrete phenomena. For instance: "Affects aren't feelings, they're becomings that spill over beyond whoever lives through them" (Deleuze, Negotiations, 137.).

${ }^{15}$ Lyotard, "The Unconscious as Mise-en-Scène," 87-88.

${ }^{16}$ Our colleague, Stephen Muecke, was quick to point out here that "the body was 'discovered' a few years back by (feminist) philosophers" (Personal correspondence, 9/4/2015).

${ }^{17}$ Godard, "Blindsight," 201. 
18 See Lyotard on the ordering of traditional creative production in his essay, "The Unconscious as Mise-en-scène," 87.

${ }^{19}$ Walser, The Walk, 14, 40, 32, 15.

${ }^{20}$ One of my favorite lines firmly locates the writer in his body: "self reproof touched me from behind my back and stood before me in my way" (Walser, The Walk, 87).

${ }^{21}$ Lyotard, "The Unconscious as Mise-en-Scène," 88.

${ }^{22}$ Davies and Hinton, All This Can Happen, 0:35:25 - 0:36:42.

${ }^{23}$ In proposing a rhythmic contour for this film, I am inspired by Yvette Biro and her ability to sketch rhythmic contours for films she analyses in her book, Turbulence and Flow. Moving beyond a linear conception of time, she describes a range of rhythmic possibilities for films and creates such a strong sense of the rhythm of each film she analyses that a topography or shape for the film emerges in my readerly imagination (Biro, Turbulence and Flow).

${ }^{24}$ The use of the term, "swerve," is intentional and with precedent. Steve Goodman, writing in the field of music, describes the swerve in relation to atoms falling vertically through space. Citing Lucretius and Serres via Deleuze, he writes that it is in swerving - in skidding out of their downwards trajectories in unpredictable waysthat atoms collide with each other and produce matter: "If it were not for this swerve, everything would fall downwards like raindrops through the abyss of space. No collision would take place and no impact of atom on atom would be created. Thus nature would never have created anything" (Goodman, Sonic Warfare, 106).

${ }^{25}$ Davies and Hinton, All This Can Happen, 0:23:06.

${ }^{26}$ Davies and Hinton, All This Can Happen, 0:23:57.

${ }^{27}$ Davies and Hinton, All This Can Happen, 0:05:50.

${ }^{28}$ Davies and Hinton, All This Can Happen, 0:27:10.

${ }^{29}$ It is important, too, to note the role that the narrator's performance plays in creating this rhythm in the film. Through a delivery that is at once emphatic and achingly delicate, the writer's highs and lows retain a wonderful complexity. They indicate at once the writer's acute passion and his careful sensitivity.

${ }^{30}$ Bahouth, Radio Interview with Hinton and Davies.

${ }^{31}$ Davies and Hinton, All This Can Happen, 0:39:40. All other quotations cited from the film are taken from the film voice-over which is adapted from Christopher Middleton's translation of the novella (London: Serpent's Tail, 1992.)

${ }^{32}$ Bahouth, Radio Interview with Hinton and Davies.

${ }^{33}$ Louppe, Poetics of Contemporary Dance, 22.

${ }^{34}$ Louppe, "Singular, Moving Geographies," 18. The "tonic muscles" are explained by Godard as those "which specialize in gravitational responses" and that contain our bodies" "most ancient memory" (Ibid.).

${ }^{35}$ Solnit, Wanderlust, 33.

${ }^{36}$ Biro, Turbulence and Flow, 37. 


\section{References}

All This Can Happen. Dir. Siobhan Davies and David Hinton. UK, 2012. Digital Video.

Bahouth, Brian. Radio Interview with David Hinton and Siobhan Davies, 2013. Accessed 24 March 2015. http://www.siobhandavies.com/watch-listen/2013/09/14/all/

Barker, Jennifer. The Tactile Eye: Touch and the Cinematic Experience. Berkeley: University of California Press, 2009.

Baudelot, Alexandra. "Jennifer Lacey and Nadia Lauro: Choreographic Dispositifs." Danse: An Anthology, Ed. Noémie Solomon. Dijon, France: Les Presses du Reel, 2014. 177-185.

Biro, Yvette. Turbulence and Flow in Film: The Rhythmic Design. Bloomington: Indiana University Press, 2008.

Brannigan, Erin. Dancefilm: Choreography and the Moving Image. New York: Oxford University Press, 2011. https://doi.org/10.1093/acprof:oso/9780195367232.001.0001

Deleuze, Gilles. Negotiations: 1972-1990. New York: Columbia University Press, 1995.

Forsythe, William. Year unspecified. "The Choreographic Object." Accessed 28/3/2015. http://www.williamforsythe.de/essay.html

Gallese, Vittorio and Michele Guerra. "Embodying Movies: Embodied Simulation and Film Studies." Cinema: Journal of Philosophy and the Moving Image 3 (2012): 183-210.

Godard, Hubert and Suely Rolnik. "Blindsight." In Peripheral Vision and Collective Body, Ed. Museion Bozen/Bolzano 177-219. Bolzano: Museion, 2008.

Goodman, Steve. Sonic Warfare: Sound, Affect, and the Ecology of Fear. Cambridge: MIT Press, 2010.

Louppe, Laurence. Poetics of Contemporary Dance. Trans. Sally Gardner. Alton: Dance Books, 2010.

. "Singular, Moving Geographies: An Interview with Hubert Godard." Writings on

Dance: The French Issue 15 (Winter 1996): 12-21. 
Lyotard, Jean-François. "The Unconscious as Mise-en-Scène." Performance in PostModern Culture. Eds. Michel Benamou and Charles Caramello, 87-98. Madison: Coda Press, 1977.

."Gesture and Commentary." Iyyun, The Jerusalem Philosophical Quarterly 42.1

(1993): 37-48.

Marks, Laura U. and Dana Polan. The Skin of the Film: Intercultural Cinema, Embodiment, and the Senses. Durham: Duke University Press, 1999.

https://doi.org/10.1215/9780822381372

Muecke, Stephen. Personal correspondence, 9/4/2015.

Pearlman, Karen. "The Rhythm of Thinking: Speculations on How an Editor Shapes the Rhythms of a Film." Metro Magazine 141 (2004): 112-116.

Shaviro, Steven. The Cinematic Body. Minneapolis: University of Minnesota Press, 1993.

Siobhan Davies Dance, "All This Can Happen." Accessed 26 March, 2015.

http://www.siobhandavies.com/work/all-this-can-happen/.

Sobchack, Vivian. Carnal Thought: Embodiment and Moving Image Culture. Berkeley: University of California Press, 2004.

Solnit, Rebecca. Wanderlust: A History of Walking (New ed.) London: Verso Books, 2002.

Stern, Lesley. “As Long As This Life Lasts." PHOTOFILE (Winter 1987): 15-19.

Taussig, Michael. Mimesis and Alterity. New York: Routledge, 1993.

Walser, Robert. The Walk. Trans. Susan Bernofsky. New York: New Directions, 2012. 